Resumo de Trabalho Acadêmico 



\section{Oficina inVENTIVA E OS DESAFIOS DO ENVELHECIMENTO SAUDÁVEL}

Vera Lygia Menezes Figueiredo ${ }^{\star}$

Palavras-chave: Envelhecimento Saudável. Estimulação Cognitivo-Expressiva. Criatividade. Oficina Inventiva.

\section{INVENTIVE WORKSHOP AND THE CHALLENGES FOR A HEALTHY AGEING.}

Keywords: Healthy Ageing. Cognitive-Expressive Stimulation. Creativeness. Inventive Workshop.

A importância de metodologias, para a prática profissional, que contemplem a promoção e a prevenção de saúde na velhice é destacada nas recomendações da Organização Mundial de Saúde para um envelhecimento ativo e participativo (WHO, 2002). Diversos estudos gerontológicos mostram resultados consensuais quanto à supremacia do estilo de vida entre os fatores de saúde e longevidade no processo de envelhecimento, destacando-se atributos como o bem-estar subjetivo, a capacidade cognitiva, a autonomia, os comportamentos positivos, etc. (SCHAIE, 1993; SCHAIE; DUTTA; WILLIS, 1999; SILVA, 2001; BASSUK; GLASS; BERKMAN, 1999; SMITS et al., 1999). A realidade demográfica brasileira, por outro lado, aponta um crescimento progressivo da população idosa, que já se aproxima de dez por cento da população total (IBGE, 2003).

Estes motivos expostos justificaram a monografia de pós-graduação lato sensu em Gerontologia e Geriatria Interdisciplinar do Centro de Ciências Médicas da UFF, aprovada em setembro de 2005, sob o título: Desenvolvimento de um método de estimulação cognitivo-emocional em grupo para a promoção de saúde na velhice.

A "Oficina Inventiva", que vem a ser a operacionalização do "Método ECEG $^{\mathcal{O}}$ " (termo abreviado), desde 2004 vem sendo oferecida à comunidade de idosos que freqüentam o Programa Interdisciplinar de Geriatria e Gerontologia do HUAP/UFF. Tem como objetivo primário a uma ampliação do potencial inventivo, por se acreditar que seja possível que a sua expansão provoque uma abertura à experiência e à flexibilidade comportamental; isto se traduz, por sua vez, em uma melhora no bem-estar subjetivo e na qualidade de vida dos indivíduos idosos participantes.

\footnotetext{
* Programa Interdisciplinar de Geriatria e Gerontologia (Prof. Dra. Vilma Duarte Câmara) do Hospital Universitário Antônio Pedro da Universidade Federal Fluminense - PIGG/HUAP/UFF. Endereço: Rua Pedro Américo, ${ }^{\circ}{ }^{\circ}$ 64, apt $^{\circ} 602$ - Catete, RJ. CEP: 22211-200.

E-mail: vely_menezes@yahoo.com.br
} 
Vera Lygia Menezes Figueiredo

Enfatizando o processo individual de experienciação no aqui-e-agora para a descoberta de novas potencialidades e na afirmação / ampliação das já existentes, a metodologia aplicada nas "oficinas inventivas" se compõe de: (a) um programa de estimulação multissensorial diversificada e em grau crescente de complexidade, oferecido com regularidade de aplicação por duas horas diárias de exercitação e ao longo de quatro meses, para grupos constituídos por no mínimo seis e no máximo quinze participantes; o grupo, por sua vez, cumpre a função de potencializar os desenvolvimentos individuais, dado o dinamismo e a sinergia intragrupo também estimulados. A aplicação do programa vai de acordo com as características de cada grupo formado, respeitando-se os limites naturais da idade e as singularidades; isto significa ter cuidados para com a fadiga mental e/ou postural, para com as possíveis reações de evitação ou de rechaço frente aos exercícios propostos, bem como as frustrações por inabilidades momentâneas, e outras possibilidades; (b) uma condução de grupo que se utiliza de um modo de facilitação não-diretivo, o que significa sustentar sempre um clima grupal encorajador e desprovido de crítica, de competitividade, ou de diretividade no fazer tanto individual como grupal.

Aprovado pela Comissão de Ética em Pesquisa do Hospital Universitário Antônio Pedro, em dezembro de 2003, o estudo experimental vem sendo conduzido com o propósito de validação futura do citado método. Espera-se que a hipótese a ser testada conduza à confirmação de que, após a aplicação do "Método ECEG ", o grupo de intervenção apresente diferença significativa em relação ao grupo controle quanto a mudanças nas atitudes e incremento das capacidades de atenção e de concentração. Até o momento, os dados coletados provenientes de três oficinas efetivadas mostram resultados preliminares promissores.

\section{REFERÊNCIAS}

BASSUK, S.S.; GLASS, T.A.; BERKMAN, L.F. Social disengagement and incident cognitive decline in community-dwelling elderly persons. Ann Intern. Med., [S.1.], v. 131, n. 3, p. 165-173, Aug. 1999. Disponível em: <http:// www.annals.org/cgi/content/full/131/3/165>. Acesso em: 18 nov. 2003.

INSTITUTO BRASILEIRO DE GEOGRAFIA E ESTATÍSTICA. Censo demográfico 2000: características gerais da população: resultados da amostra. Rio de Janeiro, 2003.

SCHAIE, K W. The Seattle longitudinal study: a thirty-five-year inquiry of adult intellectual development. Z Gerontol. [S.1.], v. 26, n. 3, p. 129-137, May/Jun. 1993.

SCHAIE, K W.; DUTTA, R.; WILLIS, S. L. Cognitive and sociodemographic risk factors for mortality in the Seattle Longitudinal Study. J Gerontol B Psychol Sci So Sci., [S.1.], v. 54, n. 5, p. 273-282, Sep. 1999.

SILVA, M. J. Autonomia e saúde mental: o desafio para uma velhice bem-sucedida. Tese (Doutorado em Enfermagem)-Biblioteca Setorial da Saúde, Universidade Federal do Ceará, Fortaleza, 2001. 
SMITS, C.H. et al. Cognitive functioning and health as determinants of mortality in an older population. Am Journal of Epidemiol, [S.1.], v. 150, n. 9, p. 978-986, 1999.

WHO - World Health Organization. Active ageing: a policy framework. Second United World Assembly on Ageing. Madrid: [s.n.], 2002.

Recebido em: novembro/2006 Aceito em: dezembro/2006 
